\title{
Continuous Air Monitor Operating Experience Review
}

\section{$18^{\text {th }}$ Topical Meeting on the Technology of Fusion Energy}

\author{
L. C. Cadwallader \\ S. A. Bruyere
}

September 2008

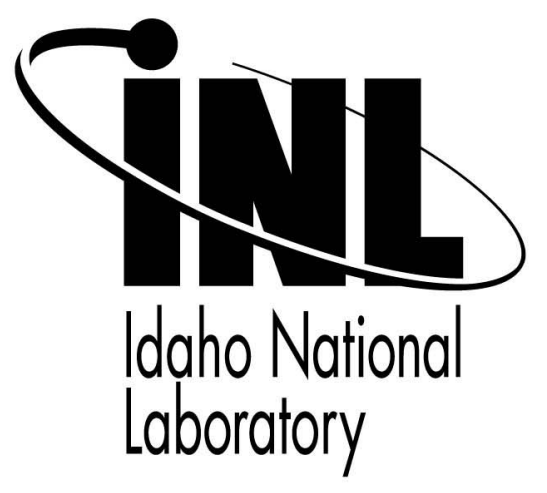

This is a preprint of a paper intended for publication in a journal or proceedings. Since changes may be made before publication, this preprint should not be cited or reproduced without permission of the author. This document was prepared as an account of work sponsored by an agency of the United States Government. Neither the United States Government nor any agency thereof, or any of their employees, makes any warranty, expressed or implied, or assumes any legal liability or responsibility for any third party's use, or the results of such use, of any information, apparatus, product or process disclosed in this report, or represents that its use by such third party would not infringe privately owned rights. The views expressed in this paper are not necessarily those of the United States Government or the sponsoring agency. 


\title{
CONTINUOUS AIR MONITOR OPERATING EXPERIENCE REVIEW
}

\author{
L. C. Cadwallader and S. A. Bruyere
}

Idaho National Laboratory, Idaho Falls, Idaho, Lee.Cadwallader@inl.gov

\begin{abstract}
Continuous air monitors (CAMs) are used to sense radioactive particulates in room air of nuclear facilities. CAMs alert personnel of potential inhalation exposures to radionuclides and can also actuate room ventilation isolation for public and environmental protection. This poper presents the results of a CAM operating experience review of the DOE Occurrence Reporting and Processing System (ORPS) database from the past 18 years. Regulations regarding these monitors are briefly reviewed. CAM location selection and operation are briefly discussed. Operating experiences reported by the U.S. Department of Energy and in other literature sources were reviewed to determine the strengths and weaknesses of these monitors. Power losses, human errors, and mechanical issues cause the majority of failures. The average "all modes" failure rate is $2.65 E-05 / h$ r. Repair time estimates vary from an average repair time of 9 hours (with spare parts on hand) to 252 hours (without spare parts on hond). These dota should support the use of CAMs in any nuclear facility, including the National Ignition Facility and the international ITER experiment.
\end{abstract}

\section{INTRODUCTION}

A continuous air monitor (CAM), also called a constant air monitor, is the basic device used to sample room air in nuclear facilities and protect workers from airborne radioactivity hazards. An early generation CAM is shown in Figure 1. The allowable radionuclide concentration limits for personnel inhalation exposure in the U.S. are given in 10CFR 20 and 10CFR $835^{1,2}$ but the means by which an employer will determine these exposures is not specified in the regulations. The longstanding, typical method for measuring the concentration of radioisotopes in air, and thus evaluating the possibility of inhalation exposure from air contamination, is to pass a measured quantity of air through a collection medium and then read the activity of whatever airborne material collects on the medium. Filter paper is typically used as the collection medium. The air flow is usually forced through the filter paper, such as by a blower or small vacuum pump. Either device moves air at a measured rate, usually about $0.5-1 \mathrm{~L} / \mathrm{sec}\left(1-2 \mathrm{ft}^{3} / \mathrm{min}\right)$, across the filter paper. A radiation detector mounted close to the

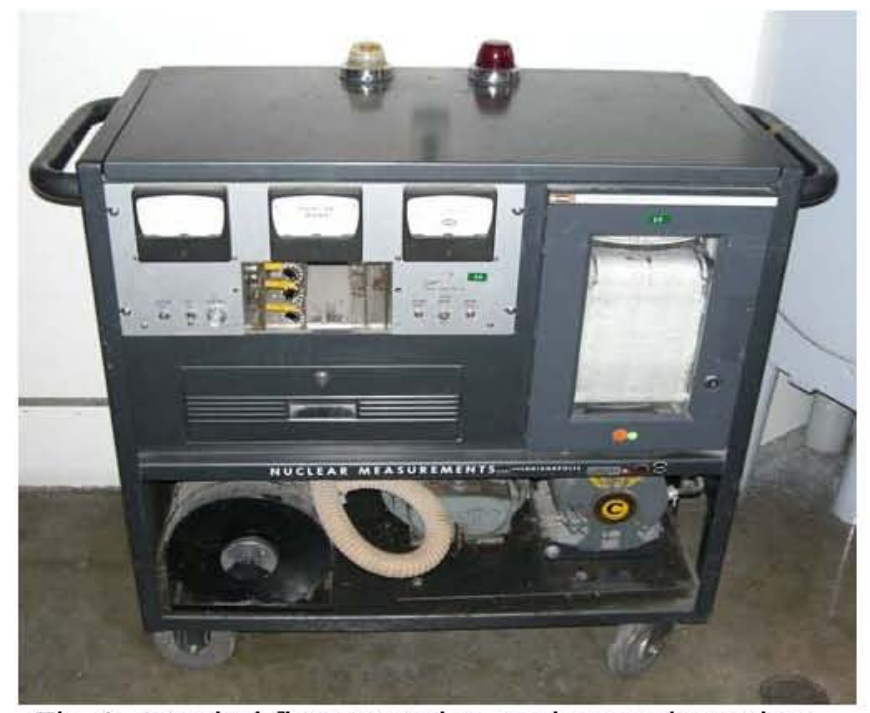

Fig. 1. A typical first generation continuous air monitor.

filter paper is used to measure the activity of any collected material. ${ }^{3}$ Radiation detectors are typically Geiger-Muller counters or scintillation counters with photomultiplier tubes.

CAMs are used to monitor for airborne contamination in nearly every nuclear and nuclear-related installation, including reactors, hot cells, fuel processing and storage buildings, waste processing and storage facilities, particle accelerators, test reactors, and fusion energy experiments. CAMs have been used for over 60 y ears. One of the earliest designs of a CAM was put in service at Oak Ridge National Laboratory. In 1944, units were set up within and outside of Oak Ridge buildings to detect iodine from radioactive lanthanum processing operations. ${ }^{4}$ Because of the widespread and long-term use of CAMs, operating experience data were readily available for this review.

It is noted that one of the most important issues regarding CAM effectiveness is location selection so the CAM unit will draw air samples that are representative of the worker breathing air. ${ }^{5,6}$ It is not uncommon to use two or more CAMs in a given room or building area; overlapping coverage ensures that if one CAM fails, the room or area is still being monitored. Overlapping 
coverage also allows multiple location samples to calculate reasonable average estimates of radionuclide concentrations in room air. Consequently, a large facility can use several dozen CAMs throughout its radiation areas. As a generality of CAM operation, a large facility will also have a small set of spare units on site; a rough rule of thumb would be up to $10 \%$ of the number of deployed CAMs to serve as replacements for failed monitors. This paper reviews monitor operating experiences and good practices and gives some reliability and maintainability values for these instruments.

\section{EXPERIENCE DATA ASSESSMENT}

The U.S. Department of Energy (DOE) operates an Occurrence Reporting and Processing System (ORPS) database to record equipment faults and human errors at DOE facilities. ${ }^{7}$ The reporting period of 1990 to the present has encompassed thousands of CAM units across the DOE Complex. A search of the database narrative descriptions for "continuous air monitor" returned 415 ORPS reports (see Table I). Some reports were deleted from this study because they described a CAM correctly responding to airborne contamination; the majority of these reports occurred during decommissioning and dismantlement activities. Other reports were deleted because they referred to stack monitors rather than room air monitors. A third subset of the reports was deleted because a CAM was mentioned but the report described some other, unrelated equipment failures. These deletions left 219 reports attributable to personnel safety CAMs. As derived from Table I, 29.7\% of failures were electrical (including loss of power and power supply problems), $26.9 \%$ of the failures were mechanical (mainly in the air pumping portion of the units), human errors gave $27.4 \%$ (roughly three errors by authorized CAM workers to each non-CAM worker error), $8.2 \%$ were radiation detector tube faults, and $7.8 \%$ of the reports were electronics faults.

In the early 1990s, Lingren and Hitzman polled nuclear power plants about radiation monitoring system performance with a questionnaire. ${ }^{8}$ Failures of GeigerMuller and photo-multiplier tubes were noted to be one of the widespread issues at the 55 plants that responded to the questionaire. This is much different than the $8.2 \%$ of detector failures shown in Table I. Reasons for this discrepancy are not clear. Operating environments would appear to be similar and should not be a factor in this difference. Perhaps manufacturing improvements occurred in the late 1990s and early 2000s.

One interesting issue is the number of CAM failures where the CAM did not annunciate a fault or otherwise issue some type of trouble alarm. In human-error-caused failures, the CAM did not annunciate $88 \%$ of the time. In
$42 \%$ of the mechanical faults and $38 \%$ of the electrical faults, the affected CAMs did not issue a trouble alarm. The only way personnel learned of the failure was either from daily testing or from an alert staff member passing by and noting that the CAM was not operating. Therefore, the periodic (daily or perhaps weekly) inspections that room air monitor CAMs receive is warranted and is a best practice for this type of instrument, at least for the presently used level of technology.

Periodic checks are warranted for other types of monitors as well. Experience data with nuclear criticality alarms showed that for a 1-year test interval, the failure of the monitoring system to alarm on demand was 1.7E-03/demand; for a 1-month test interval, the failure rate was $1.3 \mathrm{E}-04 /$ demand. $^{9}$ This is a full order of magnitude lower failure rate gained by the more frequent testing because the higher frequency of testing identifies both system faults and incipient faults or weaknesses before such faults propagate into device failure. Frequent testing that does not create additional system wear or decrease useful system life is a benefit to operational reliability and is a best practice.

\section{RELIABILITY AND MAINTAINABILITY DATA}

The ORPS reports describe the failure modes of CAM units but do not give enough information on units in use and time periods to calculate failure rates. Instead, the literature was searched for published failure rate data on air monitors. Several values were found and are given in Table II. $^{10-13}$ Also, various Idaho National Laboratory (INL) records have been reviewed and provide enough data to support an order-of-magnitude failure rate calculation. A typical count of four faults per year at an INL facility gives a point estimate of $4 /[(44$ units $)(8760 \mathrm{hr})]$ or $1.0 \mathrm{E}-05 /$ unit-hr. The $1.0 \mathrm{E}-05 /$ unit-hr failure rate range is a reasonable first approximation for the INL units in use. Taking the "all modes" failure rates in Table II and performing a geometric mean value for those data values gives 2.6E-05/unit-hr, which yields good agreement with the INL cursory value and sets a suggested "all modes" failure rate value for CAMs of 2.6E-05/unit-hr based on the literature data. The INL data also gave 16 false radiation alarm events over 13 years, so $16 /[(44$ units $)(13 \mathrm{yr})]=0.03$ false alarms per CAM-year. There were no INL events of failure to alarm when required by airborne activity. There have been too few events of airborne activity challenging the INL CAMs, so any statistical estimate of failure to alarm on demand is not meaningful. If more demands to operate had occurred, the "alarm on demand" failure rate could be calculated for INL CAMs. 
TABLE I. Continuous air monitor data from DOE events reported in ORPS

\begin{tabular}{|c|c|c|c|c|}
\hline Fault Category & Subcomponent or Error & $\begin{array}{l}\text { Fault } \\
\text { Count }\end{array}$ & $\begin{array}{l}\text { CAM } \\
\text { Alarmed } \\
\text { the Fault }^{\mathrm{a}}\end{array}$ & \begin{tabular}{|l} 
CAM Did \\
Not Alarm \\
Fault \\
\end{tabular} \\
\hline \multicolumn{5}{|l|}{ Mechanical Faults } \\
\hline Air flow problem & Seal, solenoid, tube, air hose, valve, rotometer & 11 & 6 & 5 \\
\hline $\begin{array}{l}\text { Air flow environmental } \\
\text { problem }\end{array}$ & Windstorm, dust accumulation & 7 & 0 & 7 \\
\hline Alarm & Alarm not functional & 3 & 1 & 2 \\
\hline Cabinet & Various cabinet problems & 3 & 2 & 1 \\
\hline Cabinet & Wheels & 1 & 1 & 0 \\
\hline Cabinet & Light bulb & 2 & 1 & 1 \\
\hline Maintenance alarm & Unknown fault caused alarm & 7 & 7 & 0 \\
\hline Motor & Blower motor failure/vacuum pump failure & 12 & 10 & 2 \\
\hline Motor & Blower motor switch & 2 & 1 & 1 \\
\hline Motor & Bearings & 1 & 1 & 0 \\
\hline Motor & Belt & 3 & 0 & 3 \\
\hline Recorder & Strip chart & 3 & 1 & 2 \\
\hline Timer & Timer & 1 & 0 & 1 \\
\hline $\begin{array}{l}\text { Early life faults in new } \\
\text { components }\end{array}$ & Unknown & 3 & 3 & 0 \\
\hline Subtotals & & 59 & 34 & 25 \\
\hline \multicolumn{5}{|l|}{ Electrical Faults } \\
\hline Annunciator & Panel problem, interface board & 4 & 1 & 3 \\
\hline $\begin{array}{l}\text { CAM alarm test or } \\
\text { spurious alarm }\end{array}$ & Unknown fault caused alarm failure or spurious alarm & 3 & 1 & 2 \\
\hline CAM reading & $\begin{array}{l}\text { Erratic readings to control room, unidentified electrical } \\
\text { component }\end{array}$ & 6 & 4 & 2 \\
\hline Loss of line power & $\begin{array}{l}\text { Damaged wiring from rainwater, wiring pulling loose, poor } \\
\text { connection, short circuit, fuse, sensitive power connection }\end{array}$ & 10 & 7 & 3 \\
\hline Loss of line power & Reason not listed in ORPS & 18 & 11 & 7 \\
\hline Loss of power supply & Diode shorted out & 7 & 5 & 2 \\
\hline Power supply problem & Power flux, defective supply & 6 & 1 & 5 \\
\hline Power supply problem & High voltage error & 1 & 1 & 0 \\
\hline Power supply problem & Noise interference & 8 & 8 & 0 \\
\hline Power supply problem & Pre-amplifier failed & 2 & 1 & 1 \\
\hline Subtotals & & 65 & 40 & 25 \\
\hline \multicolumn{5}{|l|}{ Electronic Faults } \\
\hline Display & Unreadable LED & 2 & 2 & 0 \\
\hline Software & Math error & 2 & 2 & 0 \\
\hline Software & Random access memory check sum error & 12 & 11 & 1 \\
\hline Software & Circulatory software error message & 1 & 1 & 0 \\
\hline Subtotals & & 17 & 16 & 1 \\
\hline \multicolumn{5}{|l|}{ Radiological Faults } \\
\hline Detector failure & Unidentified Geiger-Müller tube, photomultiplier tube fault & 16 & 11 & 5 \\
\hline Detector & Mylar torn & 1 & 1 & 0 \\
\hline Detector & Rate meter stuck & 1 & 1 & 0 \\
\hline Subtotals & & 18 & 13 & 5 \\
\hline
\end{tabular}


TABLE I. (continued).

\begin{tabular}{|c|c|c|c|c|}
\hline Fault Category & Error & $\begin{array}{l}\text { Fault } \\
\text { Count }\end{array}$ & $\begin{array}{l}\text { CAM } \\
\text { Alarmed } \\
\text { the Fault }^{\mathrm{a}}\end{array}$ & \begin{tabular}{|l|} 
CAM Did \\
Not Alarm \\
Fault
\end{tabular} \\
\hline \multicolumn{5}{|c|}{ Human Error-CAM Worker ${ }^{\mathrm{b}}$} \\
\hline Human error & $\begin{array}{l}\text { Air intake not repaired, vacuum line left off, vacuum left } \\
\text { unplugged }\end{array}$ & 2 & 0 & 2 \\
\hline Human error & Air flow set too high & 1 & 1 & 0 \\
\hline Human error & Air flow set too low & 1 & 0 & 1 \\
\hline Human error & Air flow blocked, glove on box, hand on air intake & 2 & 1 & 1 \\
\hline Box problems & Door not closed properly on CAM cabinet & 1 & 1 & 0 \\
\hline Box problems & CAM covers not replaced correctly & 1 & 0 & 1 \\
\hline Calibration & Overdue calibration & 7 & 0 & 7 \\
\hline Calibration & Wrong set-point for radiation level & 5 & 1 & 4 \\
\hline Calibration & Used wrong check source & 1 & 0 & 1 \\
\hline Human error & $\begin{array}{l}\text { Forgot to plug in, forgot to put valve line back in, forgot to } \\
\text { reopen valve, forgot to put filter paper in }\end{array}$ & 9 & 0 & 9 \\
\hline Human error & Forgot to remove from test mode & 2 & 0 & 2 \\
\hline Outside cause & Borrowed contaminated CAM to use & 1 & 0 & 1 \\
\hline Outside cause & Fail to turn building thermostat to correct temperature & 1 & 0 & 1 \\
\hline Training error & Incorrect inspection procedure followed & 4 & 0 & 4 \\
\hline Training error & CAM location placement error & 2 & 1 & 1 \\
\hline Training error & Maintenance error- dirty clogged pump & 1 & 0 & 1 \\
\hline Training error & Untrained in reading rated values & 2 & 0 & 2 \\
\hline Training error & Wrong part used & 1 & 0 & 1 \\
\hline Subtotals & & 44 & 5 & 39 \\
\hline \multicolumn{5}{|c|}{ Human Error-Non-CAM Worker ${ }^{b}$} \\
\hline Human error & Air flow blocked, covered air intake & 1 & 0 & 1 \\
\hline Human error & $\begin{array}{l}\text { Informed supervisor did not change out CAM before } \\
\text { calibration expired }\end{array}$ & 1 & 0 & 1 \\
\hline Human error & Shift manager did not reconnect vacuum pump & 1 & 0 & 1 \\
\hline Outside cause & Electrical work not pertaining to CAM dislodged leads & 1 & 1 & 0 \\
\hline Outside cause & Saw cut power & 1 & 1 & 0 \\
\hline Training error & CAM location error & 1 & 0 & 1 \\
\hline Training error & Operator did not see/understand CAM alarm & 1 & 0 & 1 \\
\hline Training error & CAM turned off, unplugged & 8 & 0 & 8 \\
\hline Training error & Unplugged vacuum pump to quiet the area & 1 & 0 & 1 \\
\hline Subtotals & & 16 & 2 & 14 \\
\hline
\end{tabular}

Regarding maintainability, a crucial piece of data is the repair time for the units. Table III gives some data gleaned from the ORPS reports on maintenance times, combined with some averaged maintenance data from INL facilities. The CAM testing times are probably most applicable across various nuclear sites.

The maintenance times have many variables, including the number of electronics or instrumentation technicians on staff that are qualified to repair a CAM, the number of spare CAM units held on site, the number of spare parts kept on hand or in stock rooms versus ordering, and delivery time to the site. Some of the INL
CAMs are very old designs (some more than 40 years old) and were manufactured by companies that have since gone out of business. The older units have created problems with component failures, requiring more and more technician time for repairs as the units reach the end of their useful lifetime. Obtaining appropriate spare parts has become problematic for these older units. Lingren and Hitzman noted the same issue of CAM obsolescence at power plants. ${ }^{8}$ Small numbers of newer, digital CAMs have been purchased annually at the INL to replace the most aged units, targeting the most crucial locations first. 
TABLE II. Radiation monitor failure rates from generic data sources.

\begin{tabular}{|l|l|l|l|l|}
\hline $\begin{array}{l}\text { Component } \\
\text { Description }\end{array}$ & Failure Mode & $\begin{array}{l}\text { Failure Rate } \\
(/ \mathrm{hr})\end{array}$ & $\begin{array}{l}\text { Upper Bound } \\
\text { Failure Rate } \\
(/ \mathrm{hr})\end{array}$ & Reference \\
\hline Radiation instrument & All modes & $1.43 \mathrm{E}-05$ & $1.99 \mathrm{E}-05$ & {$[10]$} \\
\hline & Zero or maximum output & $1.943 \mathrm{E}-06$ & $2.693 \mathrm{E}-06$ & {$[10]$} \\
\hline & No output & $0.972 \mathrm{E}-06$ & $1.347 \mathrm{E}-06$ & {$[10]$} \\
\hline & No change of output with change of input & $2.320 \mathrm{E}-06$ & $3.216 \mathrm{E}-06$ & {$[10]$} \\
\hline & Erratic output & $3.161 \mathrm{E}-06$ & $4.382 \mathrm{E}-06$ & {$[10]$} \\
\hline & High output & $1.595 \mathrm{E}-06$ & $2.211 \mathrm{E}-06$ & {$[10]$} \\
\hline & Low output & $1.595 \mathrm{E}-06$ & $2.211 \mathrm{E}-06$ & {$[10]$} \\
\hline & Incipient failure & $2.755 \mathrm{E}-06$ & $3.819 \mathrm{E}-06$ & {$[10]$} \\
\hline Radiation instrumen & All modes & $1.098 \mathrm{E}-05$ & $3.310 \mathrm{E}-05$ & {$[11]$} \\
\hline & Zero or maximum output & $2.28 \mathrm{E}-06$ & $6.86 \mathrm{E}-06$ & {$[11]$} \\
\hline & No output & No value given & & {$[11]$} \\
\hline & No change of output with change of input & $1.79 \mathrm{E}-06$ & $5.39 \mathrm{E}-06$ & {$[11]$} \\
\hline & Erratic output & $2.42 \mathrm{E}-06$ & $7.28 \mathrm{E}-06$ & {$[11]$} \\
\hline & High output & $1.21 \mathrm{E}-06$ & $3.64 \mathrm{E}-06$ & {$[11]$} \\
\hline & Low output & $1.20 \mathrm{E}-06$ & $3.64 \mathrm{E}-06$ & {$[11]$} \\
\hline & Incipient failure & $2.08 \mathrm{E}-06$ & $6.29 \mathrm{E}-06$ & {$[11]$} \\
\hline Radiation monitor & Drift & $3.82 \mathrm{E}-05$ & $1.98 \mathrm{E}-04$ & {$[12]$} \\
\hline & Failure & $3.80 \mathrm{E}-05$ & $8.32 \mathrm{E}-05$ & {$[12]$} \\
\hline CAM & All modes & $1.1 \mathrm{E}-04$ & Not given & {$[13]$} \\
\hline
\end{tabular}

TABLE III. Maintenance and repair times for CAMs. ${ }^{a}$

\begin{tabular}{|l|l|l|}
\hline Activity & Average Time & Source \\
\hline Technician performs daily check of CAM operability & $\approx 5$ minutes & INL data \\
\hline $\begin{array}{l}\text { Technician investigates a suspected false CAM alarm; checks CAM filter paper } \\
\text { with portable meter }\end{array}$ & 12 minutes & INL data \\
\hline Technician restores power to an inadvertently de-powered CAM, verifies operation & 5 minutes & INL data \\
\hline Technician performs CAM weekly filter change & 30 minutes & INL data \\
\hline Technician performs monthly CAM interlock check & 30 minutes & INL data \\
\hline Replace a failed CAM with a spare unit & 30 minutes & INL data \\
\hline & 1.9 hours & {$[7]^{\text {b }}$} \\
\hline CAM unit repair in instrument shop with spare parts on hand & 9 hours & INL data \\
\hline & 15.2 hours & {$[7]^{b}$} \\
\hline CAM unit repair in instrument shop, requires ordering parts from vendor & 10.5 days & INL data \\
\hline & 8 days & {$[7]^{b}$} \\
\hline CAM mean time to repair & 43.5 hours & {$[13]$} \\
\hline $\begin{array}{l}\text { a. These times have been averaged from a combined set of older CAMs and newer digital CAMs. The times are } \\
\text { considered to be generic for CAM units. Technician activities do not include travel time to the CAM unit. } \\
\text { b. A few of the ORPS reports gave repair times and these times were averaged for presentation in this paper. }\end{array}$ \\
\hline
\end{tabular}

As an example of the differences between sites, consider the data reported from the DOE Hanford site. ${ }^{13}$ Grigsby et al. give a mean time to repair (MTTR) value for CAMs of 43.5 hours. That value was found from a sample of four stack CAMs operating over a 2-year period; no MTTR data for room air CAMs were found in the literature. At the INL, the average CAM repair time with spare parts on hand was 9 hours; without spare parts on hand, the average was 252 hours, meaning parts procurement time drives up the CAM downtime. Averaging these two INL MTTR values gives 130.5 hours, a factor of three variance from Grigsby's value. Maintainability data can have such variability for the reasons described above.

As an example of the use of these data, consider a facility using $50 \mathrm{CAM}$ units. With the average failure rate 
of $2.65 \mathrm{E}-05 /$ unit-hour times 50 units, inverting the result gives $\approx 755$ hours for mean time between CAM failures. Therefore, the set of CAMs would experience one failure roughly once per month. Using the data from Table III shows that the MTTR is much shorter than 755 hours, so perhaps one or two spare units on hand to replace failed units is adequate (i.e., 2-4\% spares). If the CAMs are positioned to give good overlapping coverage of facility areas then no spares would be needed as replacements during calibration sessions. Otherwise, another one or two spare units might be needed for use as replacements during calibration sessions. Summing the daily, weekly, and monthly checks in Table III gives an average of $62 \mathrm{hr}$ of technician time per CAM per year.

\section{CONCLUSIONS}

The CAM experiences show that the highest percentage of failures is in power losses and in electrical components, followed by human errors and failures in the mechanical portion of these monitors. The current approach in the DOE Complex is to quickly replace a faulted unit with a spare CAM and take the out-of-service unit to an on-site shop for repairs. Daily operability checks and weekly functional tests are warranted because continuously operating CAMs, with their problems in drawing air and keeping power supplied to the unit, need frequent checks to verify proper operation. These faults are not always annunciated as trouble alarms by the CAM unit, so daily visits keep the units available to perform their tasks. Daily visits are a best practice for CAM operability.

On a positive note, the detector tubes appear to operate well. The reports only showed $8.2 \%$ detector head failures over the 18-yr time span of occurrence reports.

The literature search for CAM failure rates yielded the values given in Table II. Averaging the "all modes" failure rates produced a mean of $2.65 \mathrm{E}-05 / \mathrm{unit}-\mathrm{hr}$, which was in general agreement with experiences from the INL. This value is therefore reasonable to apply to CAM units if no component-specific, site-specific, or otherwise better data sets are available.

The failure rates and repair times are useful for personnel safety assessment and for facility radiological control planning. Given the estimated number of CAM units intended for a facility like ITER, planners can estimate an initial number of spare CAM units to have on hand. The time data for CAMs can be used to estimate the number of radiological control technicians needed to support the CAM checks and calibrations. Repair times can be used to help estimate the number of spare units needed and the size of the technician staff needed at the facility.

\section{ACKNOWLEDGMENTS}

This work was prepared for the U. S. Department of Energy, Office of Fusion Energy Sciences, under the DOE Idaho Operations Office contract number DEAC07-05ID14517.

\section{REFERENCES}

1. U.S. CODE OF FEDERAL REGULATIONS, Title 10, "Energy," Part 20, "Standards for Protection Against Radiation," Appendix B, “Annual Limits on Intake (ALIs) and Derived Air Concentrations (DACs) of Radionuclide Occupational Exposure; Effluent Concentrations; Concentrations for Release to Sewage," revision date May (2008).

2. U.S. CODE OF FEDERAL REGULATIONS, Title 10, “Energy,” Part 835, “Occupational Radiation Protection," Appendix A, "Derived Air Concentrations (DACs) for Controlling Radiation Exposure to Workers at DOE Facilities," revision date July (2007).

3. H. F. HENRY, Fundamentals of Radiation Protection, Chapter 12, John Wiley \& Sons, New York (1969).

4. AGENCY FOR TOXIC SUBSTANCES AND DISEASE REGISTRY, Public Health Assessment: Iodine-131 Releases, Center for Disease Control, National Institutes of Health, March (2008). Available at http://www.atsdr.cdc.gov/hac/pha/HCPHA.asp?State $=$ Tennessee

5. J. MISHIMA, J. HUNT, W. D. KITTINGER, G. LANGER, D. RATCHFORD, P. D. RITTER, D. ROWEN, R. G. STAFFORD, J. M. SELBY, and E. J. VALLERO, Health Physics Manual of Good Practices for the Prompt Detection of Airborne Plutonium in the Workplace, PNL-6612, Pacific Northwest National Laboratory, Richland, Washington, July (1988).

6. E. E. HICKEY, G. A. STOETZEL, D. J. STROM, G. R. CICOTTE, C. M. WIBLIN, and S. A. McGUIRE, Air Sampling in the Workplace, NUREG-1400, U.S. Nuclear Regulatory Commission, Washington, DC (1993).

7. DOE, "Occurrence Reporting and Processing System," U.S. Department of Energy, Washington, DC (2003). Available at http://www.eh.doe.gov/oeaf/orps.html Registration required.

8. C. L. LINGREN and D. F. HITZMAN, "Survey of Status and Challenges of Radiation Monitoring Systems at Nuclear Power Plants," Nuclear Science Symposium and Medical Imaging Conference, 1992, Conference Record of the 1992 IEEE, Orlando, 
Florida, October 25-31, 1992, pp. 745-747, IEEE (1993).

9. VT NUCLEAR SERVICES, LIMITED, "Specification for Standard CIDAS Mk X System," DOC-25725 Issue B, Warrington, United Kingdom, March (2008).

10. INSTITUTE OF ELECTRICAL AND

ELECTRONICS ENGINEERS STANDARD IEEE Std-500-1977, "IEEE Guide to the Collection and Presentation of Electrical, Electronic, and Sensing Component Reliability Data for Nuclear-Power Generating Stations," p. 454, New York, June (1977).

11. INSTITUTE OF ELECTRICAL AND ELECTRONICS ENGINEERS STANDARD IEEE Std-500-1984, "IEEE Guide to the Collection and Presentation of Electrical, Electronic, Sensing Component, and Mechanical Equipment Reliability Data for Nuclear-Power Generating Stations," p. 606, New York, December (1983).

12. T. G. ALBER, R. C. HUNT, S. P. FOGARTY, and J. R. WILSON, Idaho Chemical Processing Plant Failure Rate Database, INEL-95/0422, Idaho National Laboratory, Idaho Falls, Idaho, August (1995).

13. J. M. GRIGSBY, E. O. THOME, and J. YOUNG, Availability Analysis of the Ventilation Stack CAM Interlock System, RPP 5453, Revision 1, CH2M Hill Hanford Group, Hanford, Washington (2000). 